\section{EDITOR:}

- C.J. Eales, PhD

University of the Witwatersrand

\section{Assistant Editor:}

- A. Stewart, MSc

University of the Witwatersrand

\section{EDITORIAL BOARD:}

\section{National Members}

- S.L. Amosun, $\mathrm{PhD}$

University of the Western Cape

- P. Gounden, PhD

University of Durban-Westville

- M. Papadoupolos, MSc

University of Pretoria

- M. Faure, MPhil

University of Stellenbosch

- N. Mbambo, MSc

MEDUNSA

\section{INTERNATIONAL MEMBERS}

- A. Akinpelu, PhD

University College Hospital,

Ibadan, Nigeria

- T.H.A. Kolobe, PhD

University of Illinois, Chicago

- K. Shepard, PhD

Temple University, Philadelphia

- C. Partridge, $\mathrm{PhD}$

University of Kent, Canterbury

\section{Review Panel 2002:}

- Bester, Ria

- Bischof, Faith

- Bowerbank, Pat

- Crocker, Jenny

- Crous, Lynette

- David, Helen

- Diener, Ina

- Eisenberg, Masha

- Eksteen, Carina

- Fearnhead, Lynn

- Frieg, Annette

- Giraud, Jill

- Hunter, Linda

- Irwin-Carruthers, Sheena

- Jelsma, Jennifer

- Kemp, Stephanie

- M'Kumbuzi, Vyvienne

- Mothabeng, Joyce

- Mpofu, Ratie

- Naidu, Prinola

- Paulsen, Tom

- Potterton, Joanne

- Puckree, Lina

- Van Rooijen, Tania

\title{
PRESCRIPTION RIGHTS FOR PHYSIOTHERAPISTS
}

I would like to respond to the debate as to whether physiotherapists should be allowed to prescribe certain medications. My response is a resounding "yes". We physiotherapists should not be afraid of broadening our scope of practice. If we don't we might become obsolete. Medicine is constantly evolving and we should not be left behind.

There are many reasons why I support physiotherapists prescribing.

Firstly, it will benefit our patients. How many times have we seen patients on a first contact basis and recommend certain medications. How many times have physiotherapists working or travelling with sports teams been unable to treat players efficiently because of inability to prescribe or administer certain medications. Patients who need these medications have to be sent to a doctor for a prescription. This not only wastes time but is also an added cost to the patient and his or her medical aid. In the public sector it could also help by alleviating the added patient load on doctors if we could prescribe certain medications for musculoskeletal injuries (and respiratory conditions), preventing the need for referral back to the doctor. Imagine the benefit in outlying communities where doctors are a scarcity.

How will this benefit us? Well, the benefits are numerous. This would cement our first contact status. I have read various articles where first contact status of physiotherapists are under question. The bottom line is the more responsibility we are given, the more indispensable we become. Prescription rights could result in the medical fraternity regarding us as specialists of physical medicine. This added responsibility has implications on salary structures as well.

The profession will also benefit by the exposure we will get from drug companies. These drug companies market doctors and pharmacists and we also set to benefit (provided this is done within ethical boundaries). I am not saying we should routinely prescribe medications, but the option should be available to us if needed, to the benefit of our patients.

We as physiotherapists should not be afraid of change, we should embrace it. Managed healthcare is a reality and evidence based practice is the buzzword in medical circles. The effectiveness of some modalities we use is under question. Some electrotherapy modalities are now being questioned (after all Robin McKenzie himself in the book Physical therapy of the low back* by Taylor and Twomey, calls it 'the useless trappings of physiotherapy'). Why not replace those ineffective modalities and add other ways of treating our patients such as through medication. Yes it is not traditionally our scope of practice, but why can't it be. We should be looking at our patients' well-being and not hopelessly trying to stay within confines set by ourselves years ago.

Many other professions are utilizing modalities and techniques traditionally within the scope of physiotherapy. Biokineticists have almost taken over rehabilitation using exercise, massage therapists are doing most of our soft tissue techniques, and even our cousins, the occupational therapists, are doing joint mobilizations to stiff joints. They are expanding on their professions and we are trying to hang onto old regimes. Physiotherapy should evolve with changing times.

These are but a few of the benefits prescribing certain medications will have (this is provided physiotherapists are properly trained and policed, or else negative repercussions will arise). Everyone is set to benefit, from the patient to the medical aids. We need to embrace this opportunity before other professions do. It won't steer us away from being hands on, it will only make us more effective in our hands on approach.

\section{Munsief Khan}

* Taylor J.R, Twomey L.T, Physical Therapy of the low back, 3rd Edition, Churchill Livingstone, Chap.5 pg 142 


\section{Culture AND COMMUNiCATION in Health Care}

$\mathrm{A}_{\mathrm{i}}^{\mathrm{p}}$ positive disposition is a prerequisite in the daily contact with colleagues, students and patients of different cultures, but is not enough, as the optimal way of communicating does not come automatically. Communicating effectively stems from understanding the culture of the patient. It is difficult to advise on how to deal with cultural diversity in South Africa, where so many cultures exist. However, an awareness of this diversity and some knowledge of other cultures is necessary in effective communication (Gerritsen, 1998). Unstructured interviews among six Sotho speaking people (ranging from a university professor to an elderly patient) highlighted the following areas of communication which may be a problem: greeting, time perception, and choice of medical services.

Communication starts when the health worker enters the room or ward. In Western and African cultures, older people are greeted individually with the hand, while younger people can be recognized in a group. With regard to the greeting ritual one respondent stated: "It rules our lives to such an extent that if you come into a room and you find a group of people and you don't greet, there is a wall and they view you as an enemy. When you greet, they immediately respond by building bridges." In contrast to Western culture, the African culture greeting ritual is unhurried, both hands and a weak grip are used. A firm grip and eye contact might be associated with superiority and hostility. An African would hold his right elbow with his left-hand so that the other person can always see both hands and not think that one hand is held ready for attack. A weak handgrip and greeting with only the fingertips indicates confidence in the other person.

Health care workers are primarily concerned with the patient's health, but must remember that good verbal communication in the African culture entails talking about something else first. When asking the question "How are you?" the patient must be given all the time he/she needs to tell you about everything that might be on their minds - which might be very time consuming. The patient's state of health is also viewed as a private matter: “...your problem as health worker, is that in African culture in general, and the Sotho in particular, their immediate health and overall well-being is very secretive."

Time may well be the factor that causes most frustration in an intercultural contact or work situation and there is always the danger that one cultural group might regard its time perception as superior to that of another culture (Viljoen, 1996). One respondent explained that for Europeans, time is like a conveyor belt with small empty containers on it, which must be filled every 10-15 minutes, whereas Africans see time in big blocks. Europeans are always busy and must utilize their time. For Africans, time never runs out and one can make time. It might be regarded as offensive when one appears to have little time. When patients arrive for an appointment later than the specified time, they feel that they have fulfilled their duty by being there. The health care worker must not enter into a negative dialogue directly and refuse treatment, but must approach the problem in a positive, indirect way (van Niekerk, 1992). If the problem is not approached properly, conflict arises and patients might not return.

Regarding the choice of medical services, Africans follow three approaches, namely, the doctor, the sangoma and the church (van Niekerk, 1996). Many patients are not confident that doctors alone can help them. The following point of entry for a health care worker was suggested by a respondent: "I am not able to help you like a traditional healer who will tell you every thing what is wrong with you, without you telling me what is wrong with you. I can only come and help you if you co-operate."
The health care worker/patient relationship is not a clear-cut situation. The patient as well as the health worker does not always know where on the ruralurban continuum the other person is. A respondent mentioned that the African society is at cross-roads and they do not know which road to take and are somewhere in between. "When it suits us, we belong this way, and when it suits us, we belong that way." With an understanding of the different cultures, take a clue and act on it in an appropriate manner. Another respondent said that, as a professional nurse, she experienced patients as if they were wearing masks when they visit the hospital or clinics. They might not have proper clothes to put on or follow a proper diet, but will borrow clothes and tell the health personnel that they follow a certain diet - all to be acceptable to the health personnel. A situation that health care workers must be sensitive to.

It is of critical importance that all health care workers be sensitized to cultural differences. Knowledge, understanding and empathy are required for successful intercultural health care interventions.

\section{REFERENCES}

Gerritsen M 1998 The role of culture in communication: How knowledge of differences in communication between cultures may be the key to successful intercultural communication. SA Journal of Linguistics Supp135:28-50.

Van Niekerk A 1992 Saam in Afrika. Tafelberg Publishers.

Van Niekerk A 1996 Anderkant die reënboog. Tafelberg Publishers.

Viljoen A 1996 Design, identity and culture: restoring integrity. Human Resource Management 12:53.

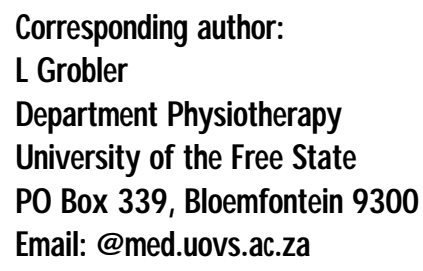

